\title{
A fast and simple protocol for synthesizing effective antimicrobial silver nanoparticles in non- specialized facilities
}

Roberto Vazquez-Munoz ( $\nabla$ roberto.bionano@gmail.com )

University of Texas at San Antonio https://orcid.org/0000-0002-3847-1305

M. Josefina Arellano-Jimenez

University of Texas at San Antonio

Jose L. Lopez-Ribot

University of Texas at San Antonio

\section{Research note}

Keywords: Silver nanoparticles, nanoantibiotics, synthesis method, AgNPs, metallic nanoparticles

Posted Date: August 24th, 2019

DOI: https://doi.org/10.21203/rs.2.13543/v1

License: (c) (1) This work is licensed under a Creative Commons Attribution 4.0 International License.

Read Full License 


\section{Abstract}

Objective Silver nanoparticles (AgNPs) can be difficult or expensive to obtain or synthesize for laboratories in resource-limited facilities. The purpose of this work was to create a fast, facile, and costeffective method for synthesizing AgNPs with potent antimicrobial properties, that can be readily implemented in non-specialized laboratories. Results Our developed method uses a rather simple and rapid chemical reduction process that involves the addition of a polyvinylpyrrolidone solution to a warmed silver nitrate solution under constant vigorous stirring, immediately followed by the addition of sodium borohydride with constant stirring for an additional 15 minutes. AgNPs had an aspect ratio close to 1 , with an average size of $6.18 \pm 5 \mathrm{~nm}$. AgNPs displayed potent antimicrobial activity, with Minimal Inhibitory Concentration values of $3 \mu \mathrm{g} \mathrm{mL}-1$ and $1.5 \mu \mathrm{g} \mathrm{mL}-1$ for Staphylococcus aureus and Candida albicans respectively.Keywords : Silver nanoparticles, nanoantibiotics, synthesis method, AgNPs, metallic nanoparticles

\section{Background}

Silver nanoparticles (AgNPs) are one of the nanomaterials more often synthesized and used in a wide diversity of products and applications worldwide (1-4), particularly as nanoantibiotics - nanomaterials with antimicrobial properties- $(5,6)$. AgNPs exert antiviral properties (7-9) and broad antimicrobial activity against a diverse array of bacteria, fungi, and protozoa (10-14).

AgNPs are commercially available from diverse companies, (3) most of them USA-based, and their cost and obtainability may vary due to different factors. Particularly for laboratories in resource-limited countries, AgNPs can be difficult or expensive to obtain. Typical nanoparticles physical presentations are suspensions or dry powders. Suspensions are typically low-concentrated, making them unsuitable for antimicrobial assays. Although highly concentrated suspensions can be prepared from powders, these are more expensive.

Some individual laboratories, mostly in the fields of Physics, Chemistry of Materials Engineering, synthesize their own AgNPs preparations, for which highly sophisticated and specialized instrumentation is often required. Yet, replicating the synthesis methods may pose a challenge for non-dedicated laboratories, due to the cost and access to reagents and equipment. Therefore, the purpose of this work is to develop a fast, facile, and non-expensive method for synthesizing AgNPs, intended for biological research purposes, biomedical applications, and for nanotechnology education $(15,16)$. Such a method can democratize research on AgNPs and their biomedical applications in laboratories across the world, particularly those non-specialized laboratories without access to sophisticated equipment, as well as those in resource-limited regions of the world.

\section{Methods}


Reagents and strains. Silver nitrate $\left(\mathrm{AgNO}_{3}\right)$, sodium borohydride $\left(\mathrm{NaBH}_{4}\right)$, and Polyvinylpyrrolidone (PVP) were acquired from Sigma Aldrich (MO). The microbial strains were the Gram-positive bacterium Staphylococcus aureus strain UAMS- 1 and the dimorphic yeast Candida albicans strain SC5314. Frozen stocks of $S$. aureus strain UAMS-1 were subcultured onto tryptic soy agar (TSA) plates (BD Difco, MD) and were used to propagate the bacterial microorganisms in $10 \mathrm{ml}$ of tryptic soy broth (TSB) (BD Difco, $\mathrm{MD}$ ) in an orbital shaker at $37^{\circ} \mathrm{C}$ overnight. C. albicans strain SC5314, stored at $-80^{\circ} \mathrm{C}$ in glycerol stock, was cultured on yeast extract-peptone-dextrose (YPD) agar plates (BD Difco, MD) and incubated at $37^{\circ} \mathrm{C}$ for $24 \mathrm{~h}$. A loopful of cells from the YPD plates was inoculated into $20 \mathrm{ml}$ of YPD liquid media and grown in an orbital shaker at $30^{\circ} \mathrm{C}$ overnight. Cells from these cultures were used to prepare the initial inocula for susceptibility tests.

AgNPs synthesis: AgNPs were synthesized by a chemical reduction process. The detailed synthesis protocol is provided in the Results section.

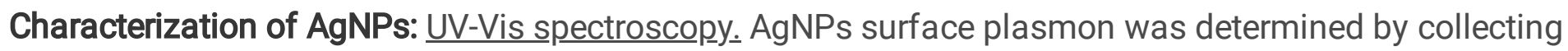
the absorbance profile in a range 250 to $650 \mathrm{~nm}$ wavelength, in $1 \mathrm{~nm}$ steps, using a UV-Vis-NIR Cary 500, (Agilent Technologies). Dynamic Light Scattering_(DSL)_Analysis. A DLS analysis was performed to analyze the AgNPs Hydrodynamic size and the Zeta potential, using a Zetasizer Nano ZS (Malvern). HighResolution Transmission Electron Microscopy_(HR-TEM). AgNPs were mounted in thin Type-B Carboncoated copper grids (Ted Pella) and analyzed in a JEOL 2010-F HR-TEM, with an accelerating voltage of $200 \mathrm{kV}$. The shape and size of the AgNPs were defined using the HR-TEM images, while the structural lattice was determined using the Selected Area Electron Diffraction (SAED) analysis. Energy_Dispersive Xray spectroscopy_(EDS). Elemental characterization was performed via an EDS analysis, using an EDAX EDS detector in the JEOL 2010-F HR-TEM.

AgNPs susceptibility tests: Antimicrobial assays were performed based on the Clinical Laboratory Standards Institute (CLSI) M09 and M27 protocols for S. aureus and C. albicans, respectively $(17,18)$, with

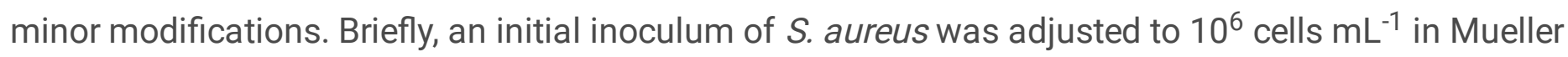
Hinton (MH) broth, whereas $C$. albicans initial inoculum was prepared by adjusting to $10^{3}$ cells $\mathrm{mL}^{-1}$ in RPMI 1640 culture media (Corning ${ }^{\circledR}$; Cellgro ${ }^{\circledR}, V A$ ) with 165 mM morpholinepropanesulfonic acid (MOPS, Thermo-Fisher Scientific, Waltham, MA) at pH 6.9. Then, $50 \mu \mathrm{L}$ of the initial inocula were added to wells of 96 well microtiter plates. AgNPs were prepared in a two-fold dilution series in either MH (for $S$. aureus) or RPMI (for $C$. albicans) media. Immediately, $50 \mu \mathrm{L}$ of the AgNPs dilution series were added to the multi-well plates containing the microbial inocula. AgNPs final concentration range from 0.375 to 192 $\mu \mathrm{g} \mathrm{mL} \mathrm{L}^{-1}$. Plates were cultured at $37^{\circ} \mathrm{C}$, at $180 \mathrm{rpm}$, for $24 \mathrm{~h}$ for $S$. aureus and at $35^{\circ} \mathrm{C}$ for $48 \mathrm{~h}$, for $C$. albicans. Minimal Inhibitory Concentration (MIC) was set as the point were no turbidity was visibly observed. The Minimal Bactericidal Concentration (MBC) and Minimal Fungicidal Concentration (MFC) were also determined. To this end, after reading the plates, $10 \mu \mathrm{l}$ from each well containing the different dilutions of AgNPs as well as control wells, were subcultured, in TSA and YPD agar plates, for $S$. aureus a C. albicans, respectively; and these plates were incubated for $24 \mathrm{~h}$ at $37^{\circ} \mathrm{C}$. MBC and MFC were set as the 
lowest concentration of AgNPs that showed fewer than three colony-forming units (CFUs) in these assays.

Assessment of the AgNPs stability: The AgNPs in liquid suspension were stored at $4^{\circ} \mathrm{C}$ in the dark. AgNPs stability over time was determined by measuring the UV-Vis profile and evaluating the antimicrobial activity, every two weeks, for 18 weeks, after the initial synthesis. Changes in UV-Vis spectra were estimated analyzing the area under the curve within the wavelength range from 320 to $600 \mathrm{~nm}$, using GraphPad software.

\section{Results And Discussion}

Synthesis of the PVP-AgNPs: AgNPs were synthesized by the chemical reduction of the silver ions. The following stock solutions were prepared using Milli-Q water: $15 \mathrm{mM} \mathrm{AgNO}_{3}, 3 \mathrm{mM} \mathrm{PVP} \mathrm{K-10}$, and $\mathrm{NaBH}_{4}$ at different concentrations from 4 to $50 \mathrm{mM}$. The PVP is the coating agent, while the $\mathrm{NaBH}_{4}$ is the reducing agent. A detailed description for the PVP K-10 and the $\mathrm{NaBH}_{4}$ characteristics is provided at the supplementary materials section.

The following is a step-by-step description of the synthesis protocol. First, $30 \mathrm{~mL}$ of the $15 \mathrm{mM} \mathrm{AgNO}_{3}$ stock solution, under vigorous stirring, were warmed at $70 \pm 5^{\circ} \mathrm{C}$. Second, $5 \mathrm{~mL}$ of $30 \mathrm{mM}$ PVP were added to the $\mathrm{AgNO}_{3}$ solution, while maintaining under vigorous stirring. Third, immediately after, $300 \mu \mathrm{L}$ $\mathrm{NaBH}_{4}$ were added dropwise to the colorless solution until it turned to a brown or a grayish color (depending on the $\mathrm{NaBH}_{4}$ concentration). The $\mathrm{NaBH}_{4}$ solutions were prepared fresh immediately before their use to avoid loss of activity. It is important to add the $\mathrm{NaBH}_{4}$ slowly since it induces an exothermic reaction that can generate a lot of heat and increase the temperature of the solution. The color change is associated with the AgNPs formation, while the turbidity can be used to conjecture if the nanoparticles are highly concentrated. Fourth, the suspension was vigorously stirred for an additional 15 minutes at 70 $\pm 5^{\circ} \mathrm{C}$. Finally, the AgNPs were transferred to a light-protected (i.e. wrapped in aluminum foil) Falcon ${ }^{\circledR}$ plastic tube and left to cool down at room temperature, and then stored at $4{ }^{\circ} \mathrm{C}$.

AgNPs are synthesized regardless of the concentration range of $\mathrm{NaBH}_{4}$ used in this work. Yet, concentration, size, and shape of AgNPs vary according to the molar ratio of $\mathrm{NaBH}_{4}$ : Ag. The different synthesis displayed similar antimicrobial activity, as seen in other works $(19,20)$. For the subsequent physicochemical characterization described in the following sections, the evaluated PVP-AgNPs were those synthesized with the lowest $\mathrm{NaBH}_{4}$ concentration (4 mM).

Characterization of the resulting PVP-AgNPs: UV-Vis spectrophotometry: the absorbance profile had a single peak with a maximum absorbance at $\bigotimes=401 \mathrm{~nm}$, typical for small spheroid AgNPs (Figure 2A). The $\mathrm{AgNO}_{3}$ absorbance profile indicated its conversion to AgNPs.

HR-TEM analysis: HR-TEM images reveal that the majority of AgNPs exhibit aspect ratio close to 1.

(Figure 2B). Defined shapes, such as trunked pyramids, were observed in significantly low numbers. The 
AgNPs have an average size of $6.18 \pm 5 \mathrm{~nm}$, ranging from 1 to $75 \mathrm{~nm}$, and $>90 \%$ fell within the 1 to $10 \mathrm{~nm}$ range ( $n=1,025$ counted nanoparticles) (Figure 2B, insert). Few large particles ( $>100 \mathrm{~nm})$ and conglomerates were sporadically observed. The EDS chemical composition analysis detected the characteristic X-ray energy bands from silver at $2.984 \mathrm{KeV}(\mathrm{La})$, and at 22.163 (Ka) (Figure 2C). HR-TEM unveiled the detailed lattice of AgNPs (Fig. 3A). The SAED analysis displayed the d-spacing of 2.36, 2.04, and $1.44 \mathrm{~nm}$, corresponding to the hkl planes $\{202,200,111\}$, respectively (Fig. 3B), according to the standard powder diffraction card of the JCPDS, silver file No. 04-0783. The distance between fringes is $2.9 \AA$, confirming a face-centered cubic (fcc) crystalline structure (Fig. $3 \mathrm{C}$ ).

Dynamic Light Scattering. The hydrodynamic size (HS) of the PVP-AgNPs was $35.18 \pm \mathrm{nm}$ and their Zeta potential $-16.2 \mathrm{mV}$. The HS is greater than their metallic core size (35.18 nm and $6.18 \mathrm{~nm}$, respectively), revealing that most of the particle volume $(>65 \%)$ is in the extended PVP-chains coating. The Zeta potential revealed that AgNPs have a negative surface charge and a low stability score (stability for colloids is achieved at $>|30| \mathrm{mV}$ ). Our Zeta value is similar to the values reported in other studies: -18.4 $\mathrm{mV}$ by Silva et al $(21)$, and +13.4 by Romero-Urbina et al (10). Also, The Zeta potential of commercial nanoparticles are close to ours: for Sigma-Aldrich AgNPs (cat. No. 484059 ) is $+0.91 \mathrm{mV}$, according to Park et al (22), and for Vector Vita PVP-AgNPs is - $14.1 \mathrm{mV}$ (19). Higher Zeta potential values have been reported: $-31 \mathrm{mV}$ by Orlowski et al (23) and $-45 \mathrm{mV}$ by Sondi et al (24).

Antimicrobial activity of the synthesized AgNPs: PVP-AgNPs exhibited potent antimicrobial activity against both $S$. aureus and $C$. albicans. $S$. aureus is a leading cause of hospital bacterial infections (25) while $C$. albicans is an opportunistic pathogenic fungus and the main causative agent of candidiasis, affecting an increasing number of immunosuppressed and medically compromised patients, with unacceptably high mortality rates $(26,27)$. The MIC values for these PVP-AgNPs were $3 \mu \mathrm{g} \mathrm{mL}^{-1}$ and 1.5 $\mu \mathrm{g} \mathrm{mL} \mathrm{L}^{-1}$ for $S$. aureus and $C$. albicans, respectively. The antimicrobial activity of our synthesized PVPAgNPs is comparable to other reported in different studies, using similar culture conditions. MIC values in the literature range from $0.8 \mu \mathrm{g} \mathrm{mL}^{-1}$ to $13.5 \mu \mathrm{g} \mathrm{mL}^{-1}$ for $S$. aureus (Table S1, supplementary material) $(13,28)$, and from $0.4 \mu \mathrm{g} \mathrm{mL}^{-1}$ to $40 \mu \mathrm{g} \mathrm{mL}^{-1}$ for $C$. albicans (Table S2, supplementary material) $(29,30)$. The physicochemical properties of AgNPs depend upon their morphology and capping agent; yet different AgNPs with different traits may display close antimicrobial activity (19). The MBC for $S$. aureus was $3 \mu \mathrm{g} \mathrm{mL}^{-1}$, while the MFC for $C$. albicans was $1.5 \mu \mathrm{g} \mathrm{mL}^{-1}$. For our AgNPs, the Microbicidal and the Inhibitory Concentrations were the same for each strain.

Stability and antimicrobial activity of the synthesized silver nanoparticles after storage. AgNPs surface plasmon changed at week 6 , showing a difference of $11.9 \%$ on their absorbance spectra when compared to the original profile (Figure 3). The AgNPs absorbance profile showed another change at week 18, yet the antimicrobial activity remained unchanged since the initial synthesis.

\section{Limitations}


- the stability and shape mono-dispersity of these PVP AgNPs is lower than others prepared by more sophisticated methods.

- The AgNPs suspension also contains other silver species, sub-product from the synthesis. These can be removed by washing the AgNPs.

- AgNPs cytotoxicity on human cells has not been yet evaluated.

\section{Abbreviations}

$\mathrm{AgNO}_{3}:$ Silver nitrate.

AgNPs: silver nanoparticles.

CLSI: Clinical Laboratory Standards Institute.

DSL: Dynamic Light Scattering.

EDS: Energy Dispersive X-ray spectroscopy.

HR-TEM: High-Resolution Transmission Electron Microscopy.

JCPDS: Joint Committee on Powder Diffraction Standards

MBC: Minimal Bactericidal Concentration.

MFC: Minimal Fungicidal Concentration.

MIC: Minimal Inhibitory Concentration.

$\mathrm{NaBH}_{4}$ : Sodium borohydride.

PVP: Polyvinylpyrrolidone.

SAED: Selected Area Electron Diffraction.

\section{Declarations}

Acknowledgments. We are grateful to the UTSA colleagues Dr. James Boyd and Dr. Gabriela RomeroUrbina for granting access to the UV-Vis spectrophotometer and the Zetasizer instruments, respectively.

Authors' contributions. RV-M designed the study. RV-M, MJA-J, and JLL-R analyzed the data. All authors contributed to the draft and revise the manuscript for intellectual content. All authors read and approved the final manuscript.

Funding. RV-M acknowledges the receipt of a postdoctoral scholarship from the Mexican Council of Science and Technology of Mexico (Conacyt). Support in the laboratory was provided by the Margaret 
Batts Tobin Foundation, San Antonio, TX, USA (to JLL-R). The funders had no role in study design, data collection, and analysis, decision to publish, or preparation of the manuscript, and the content is solely the responsibility of the authors.

Competing interests. The authors declare they have no competing interests of any sort.

Availability of data and materials. Not applicable.

Ethics approval and consent to participate. Not applicable.

Consent for publication. Not applicable.

\section{References}

1. Vance ME, Kuiken T, Vejerano EP, McGinnis SP, Hochella MF, Hull DR. Nanotechnology in the real world: Redeveloping the nanomaterial consumer products inventory. Beilstein J Nanotechnol. 2015;6(1):1769-80.

2. Tulve NS, Stefaniak AB, Vance ME, Rogers K, Mwilu S, LeBouf RF, et al. Characterization of silver nanoparticles in selected consumer products and its relevance for predicting children's potential exposures. Int J Hyg Environ Health [Internet]. 2015 May [cited 2019 Apr 24];218(3):345-57. Available from: https://linkinghub.elsevier.com/retrieve/pii/S143846391500019X

3. Nanowerk Database. Nanoparticle Database - Single-element nanoparticles [Internet]. 2019 [cited 2019 May 3]. Available from: https://www.nanowerk.com/nanoparticle_database.php

4. Syafiuddin A, Salmiati, Salim MR, Beng Hong Kueh A, Hadibarata T, Nur H. A Review of Silver Nanoparticles: Research Trends, Global Consumption, Synthesis, Properties, and Future Challenges. J Chinese Chem Soc [Internet]. 2017 Jul 1 [cited 2019 Mar 24];64(7):732-56. Available from: http://doi.wiley.com/10.1002/jccs.201700067

5. Crucho CIC. The Attack of the Smart Particles: Should Bacteria Be Afraid? ACS Med Chem Lett. 2018;9(1):2-3.

6. Weissig V, Pettinger TK, Murdock N. Nanopharmaceuticals (part 1): products on the market. Vol. 9, International journal of nanomedicine. 2014.

7. Bogdanchikova N, Vázquez-Muñoz R, Huerta-Saquero A, Pena-Jasso A, Aguilar-Uzcanga G, PicosDíaz PL, et al. Silver nanoparticles composition for treatment of distemper in dogs. Int J Nanotechnol. 2016;13(1-3).

8. Elechiguerra JL, Burt JL, Morones JR, Camacho-Bragado A, Gao X, Lara HH, et al. Interaction of silver nanoparticles with HIV-1. J Nanobiotechnology. 2005;3:1-10.

9. Galdiero S, Falanga A, Vitiello M, Cantisani M, Marra V, Galdiero M. Silver nanoparticles as potential antiviral agents. Molecules. 2011;16(10):8894-918.

10. Romero-Urbina DG, Lara HH, Velázquez-Salazar JJ, Arellano-Jiménez MJ, Larios E, Srinivasan A, et al. Ultrastructural changes in methicillin-resistant Staphylococcus aureus induced by positively 
charged silver nanoparticles. Beilstein J Nanotechnol [Internet]. 2015 [cited 2019 Apr 17];6:2396405. Available from: http://www.ncbi.nlm.nih.gov/pubmed/26734530

11. Kvitek L, Vanickova M, Panacek A, Soukupova J, Dittrich M, Valentova E, et al. Initial Study on the Toxicity of Silver Nanoparticles (NPs) against Paramecium caudatum. J Phys Chem C [Internet]. 2009;113(11):4296-300. Available from:

http://dx.doi.org/10.1021/jp808645e\%5Cnhttp://pubs.acs.org/doi/full/10.1021/jp808645e

12. Perween N, Khan HM, Fatima N. Silver nanoparticles: an upcoming therapeutic agent for the resistant Candida infections. 2019 [cited 2019 Mar 24]; Available from: http://medcraveonline.com

13. Esmaeillou M, Zarrini G, Ahangarzadeh Rezaee M, Shahbazi Mojarrad J, Bahadori A. Vancomycin Capped with Silver Nanoparticles as an Antibacterial Agent against Multi-Drug Resistance Bacteria. Adv Pharm Bull [Internet]. 2017 Sep [cited 2019 Apr 6];7(3):479-83. Available from: http://www.ncbi.nlm.nih.gov/pubmed/29071232

14. Patra JK, Baek KH. Antibacterial activity and synergistic antibacterial potential of biosynthesized silver nanoparticles against foodborne pathogenic bacteria along with its anticandidal and antioxidant effects. Front Microbiol. 2017;8(FEB):1-14.

15. Jackman JA, Cho D-J, Lee J, Chen JM, Besenbacher F, Bonnell DA, et al. Nanotechnology Education for the Global World: Training the Leaders of Tomorrow. ACS Nano [Internet]. 2016 Jun 28 [cited 2019 Jun 26];10(6):5595-9. Available from: http://pubs.acs.org/doi/10.1021/acsnano.6b03872

16. Tamez Ramírez M del S, Vega-Cantú YI. Nanotechnology learning through product development. Int J Interact Des Manuf [Internet]. 2019 Apr 9 [cited 2019 May 1];1-15. Available from: http://link.springer.com/10.1007/s12008-019-00561-y

17. CLSI. M27. Reference Method for Broth Dilution Antifungal Susceptibility Testing of Yeasts. [Internet]. 4th ed. Alexander BD, editor. Wayne, PA: Clinical Laboratory Standards Institute; 2017. Available from: https://clsi.org/standards/products/microbiology/documents/m27/

18. CLSI. M07. Methods for Dilution Antimicrobial Susceptibility Tests for Bacteria That Grow Aerobically [Internet]. 11th ed. Weinstein MP, editor. Wayne, PA; 2018. Available from: https://clsi.org/standards/products/microbiology/documents/m07/

19. Vazquez-Muñoz R, Borrego B, Juárez-Moreno K, García-García M, Mota Morales JD, Bogdanchikova $\mathrm{N}$, et al. Toxicity of silver nanoparticles in biological systems: Does the complexity of biological systems matter? Toxicol Lett. 2017;276:11-20.

20. Raza MA, Kanwal Z, Rauf A, Sabri AN, Riaz S, Naseem S. Size- and Shape-Dependent Antibacterial Studies of Silver Nanoparticles Synthesized by Wet Chemical Routes. Nanomater (Basel, Switzerland) [Internet]. 2016 Apr 15 [cited 2019 Mar 6];6(4). Available from: http://www.ncbi.nlm.nih.gov/pubmed/28335201

21. Silva E, M. Saraiva S, P. Miguel S, Correia IJ. PVP-coated silver nanoparticles showing antifungal improved activity against dermatophytes. J Nanoparticle Res. 2014;16(11).

22. Park EJ, Yi J, Kim Y, Choi K, Park K. Silver nanoparticles induce cytotoxicity by a Trojan-horse type mechanism. Toxicol Vitr [Internet]. 2010;24(3):872-8. Available from: 
http://dx.doi.org/10.1016/j.tiv.2009.12.001

23. Orlowski P, Zmigrodzka M, Tomaszewska E, Ranoszek-Soliwoda K, Czupryn M, Antos-Bielska M, et al. Tannic acid-modified silver nanoparticles for wound healing: the importance of size. Int $\mathrm{J}$ Nanomedicine [Internet]. 2018 [cited 2019 Apr 6];13:991-1007. Available from:

http://www.ncbi.nlm.nih.gov/pubmed/29497293

24. Sondi I, Goia D V., Matijević E. Preparation of highly concentrated stable dispersions of uniform silver nanoparticles. J Colloid Interface Sci. 2003;260(1):75-81.

25. Corey GR. Staphylococcus aureus Bloodstream Infections: Definitions and Treatment. Clin Infect Dis [Internet]. 2009 May 15;48(s4):S254-9. Available from: https://academic.oup.com/cid/articlelookup/doi/10.1086/598186

26. Banerjee SN, Emori TG, Culver DH, Gaynes RP, Jarvis WR, Horan T, et al. Secular trends in nosocomial primary bloodstream infections in the United States, 1980-1989. Am J Med. 1991;

27. Gudlaugsson O, Gillespie S, Lee K, Berg J V., Hu J, Messer S, et al. Attributable Mortality of Nosocomial Candidemia, Revisited. Clin Infect Dis. 2003;

28. Suchomel P, Kvitek L, Panacek A, Prucek R, Hrbac J, Vecerova R, et al. Comparative Study of Antimicrobial Activity of AgBr and Ag Nanoparticles (NPs). PLoS One. 2015;10(3):1-16.

29. Monteiro DR, Silva S, Negri M, Gorup LF, De Camargo ER, Oliveira R, et al. Silver nanoparticles: Influence of stabilizing agent and diameter on antifungal activity against Candida albicans and Candida glabrata biofilms. Lett Appl Microbiol. 2012;54(5):383-91.

30. Radhakrishnan VS, Dwivedi SP, Siddiqui MH, Prasad T. In vitro studies on oxidative stressindependent, Ag nanoparticles-induced cell toxicity of Candida albicans, an opportunistic pathogen. Int J Nanomedicine [Internet]. 2018 [cited 2019 May 6];13(T-NANO 2014 Abstracts):91-6. Available from: http://www.ncbi.nlm.nih.gov/pubmed/29593404

\section{Figures}


A UV-Vis profile of PVP-AgNPs
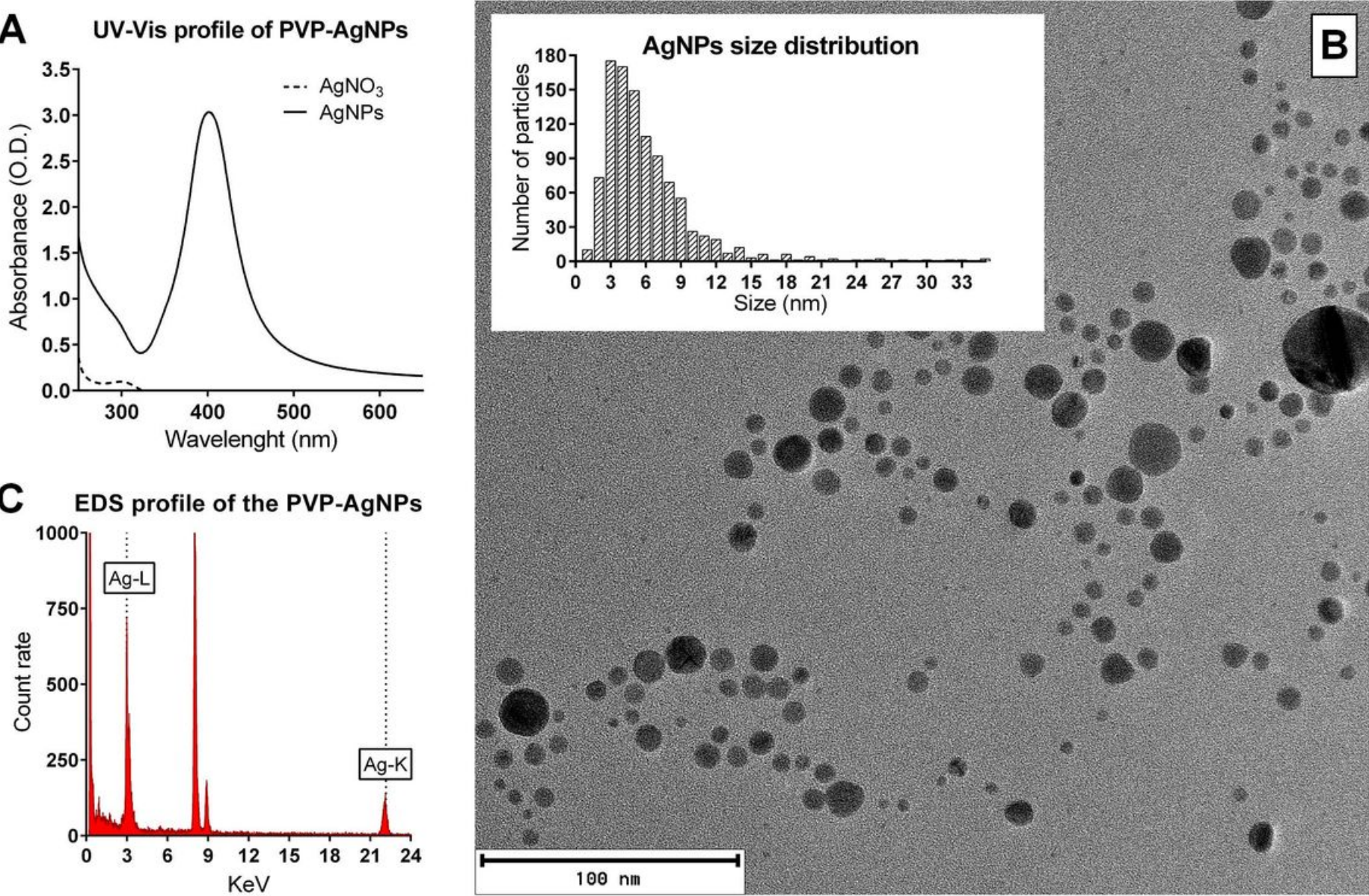

C EDS profile of the PVP-AgNPs

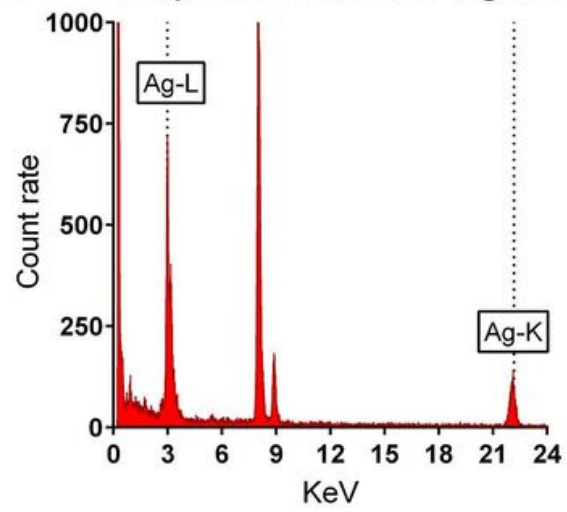



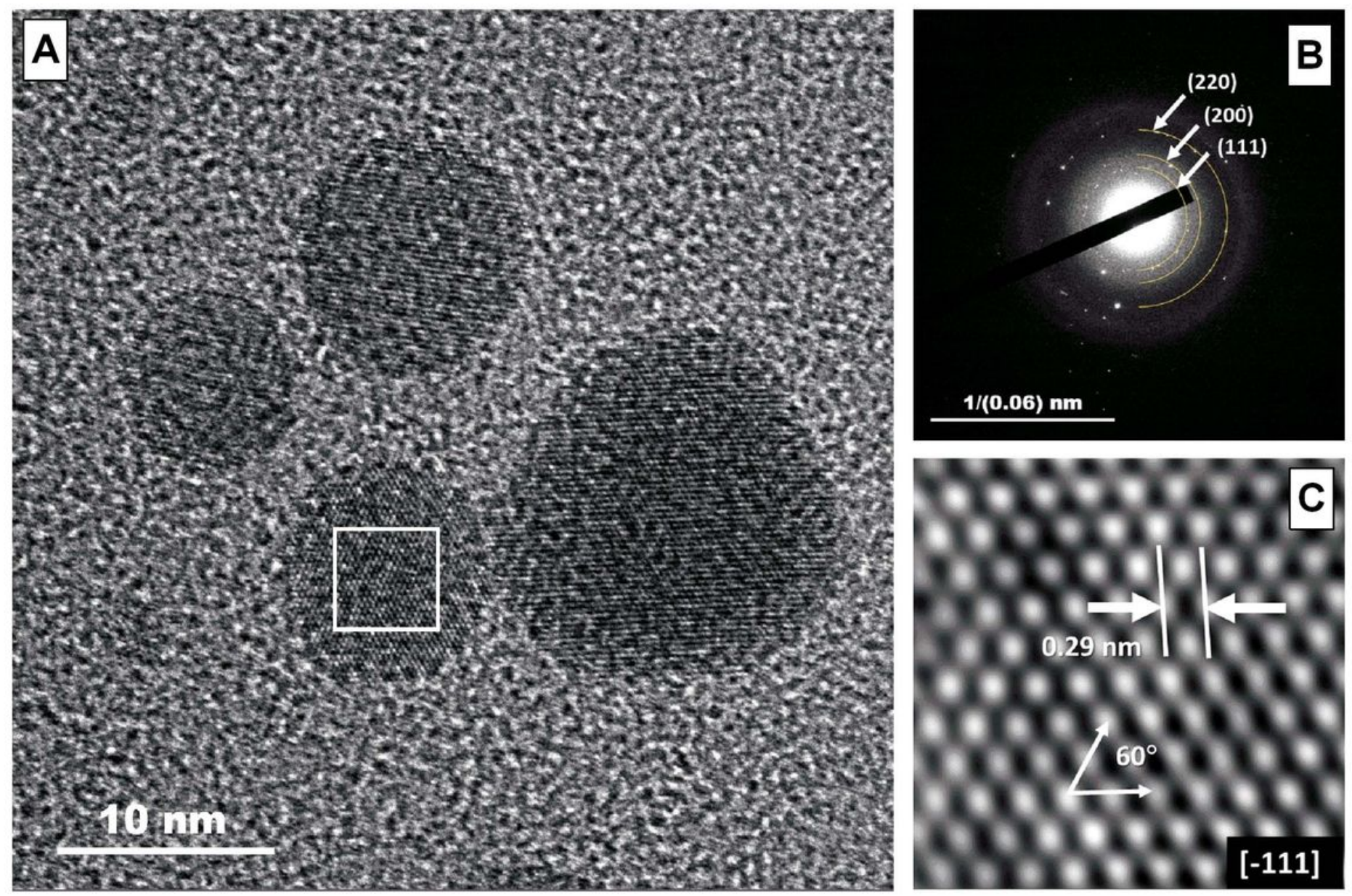

\section{Figure 2}

AgNPs Structural lattice. HR-TEM shows that AgNPs are crystalline (A). The Selected Area Electron Diffraction (SAED) shows that AgNPs the hkl planes $\{202,200,111\}$ (B). HR-TEM reveals that AgNPs dspacing is $2.9 \AA$, with crystalline structure type fcc (C). 


\section{AgNPs optical stability over time}

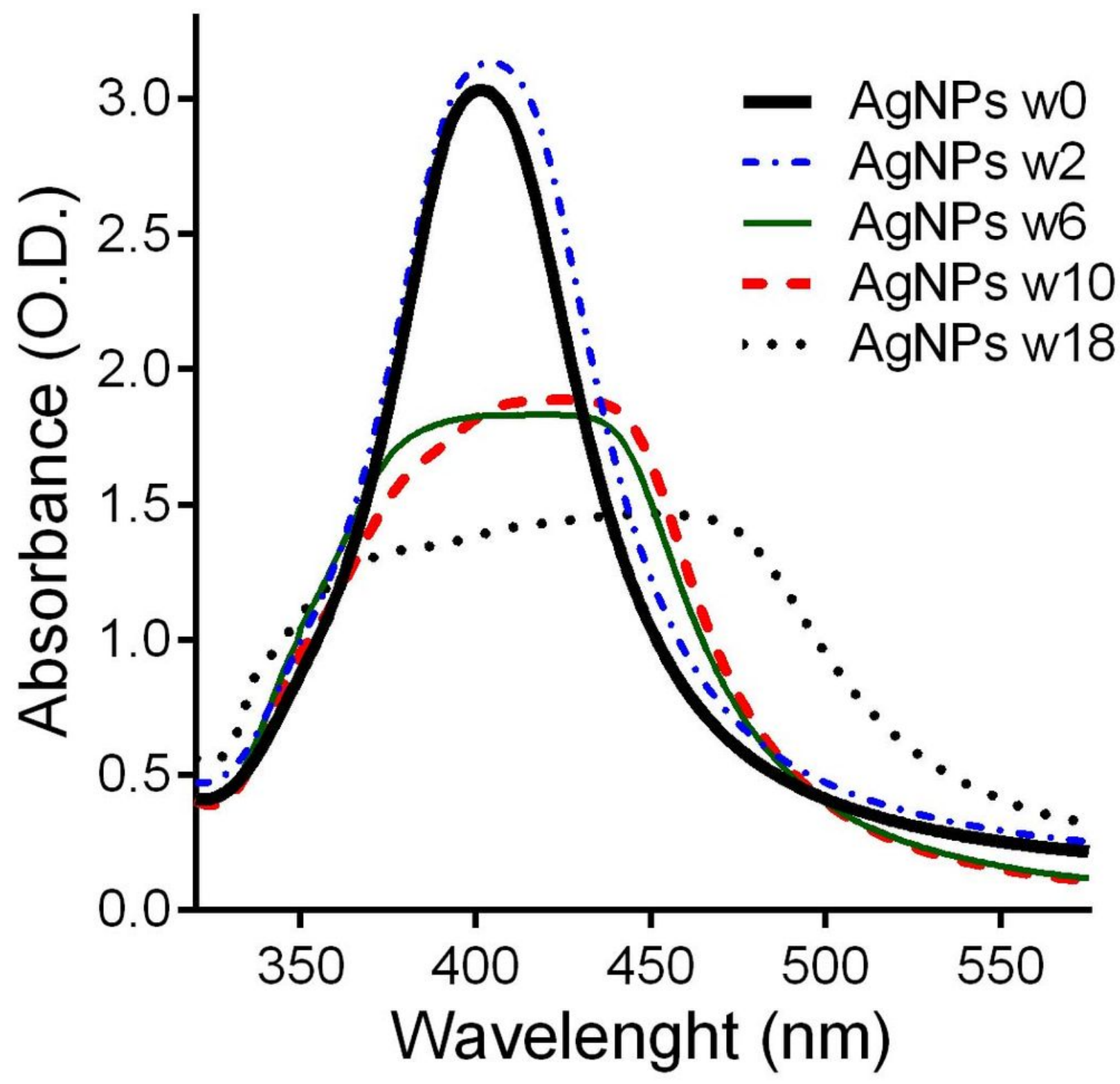

Figure 3

AgNPs optical stability over time. The surface plasmon of the silver nanoparticles exhibited remained unchanged until week 6 , showing a change in the absorbance profile; at week 18 the profile presented another change.

Supplementary Files 
This is a list of supplementary files associated with this preprint. Click to download.

- Sup.mat.forAgNPssynthesisBMCnotesEdit.docx 